\title{
Expression of the Wnt signaling system in central nervous system axon guidance and regeneration
}

\section{Edmund R. Hollis II and Yimin Zou*}

Neurobiology Section, Biological Sciences Division, University of California, San Diego, La Jolla, CA, USA

\section{Edited by:}

Simone Di Giovanni,

University of Tuebingen, Germany

Reviewed by:

Jeroen Pasterkamp, University Medical Center Utrecht, Netherlands Andrea Wizenmann, University of

Tuebingen, Germany

*Correspondence:

Yimin Zou, Neurobiology Section,

Biological Sciences Division,

University of California, San Diego,

La Jolla, CA 92093, USA

e-mail:yzou@ucsd.edu
Wnt signaling is essential for axon wiring throughout the development of the nervous system in vertebrates and invertebrates. In rodents, Wnts are expressed in gradients that span the entire anterior-posterior (A-P) axis in the spinal cord and the medial-lateral axis in the superior colliculus. In the brainstem, Wnts are expressed in more complex gradients along the A-P axis. These gradients provide directional information for axon pathfinding and positional information for topographic mapping and are detected by cell polarity signaling pathways in the growth cone. The gradient expression of Wnts and the coordinated expression of Wnt signaling systems are regulated by mechanisms which are currently unknown. Injury to the adult spinal cord results in the re-induction of Wnts in multiple cell types around the lesion site and their signaling system in injured axons. The re-induced Wnts form gradients around the lesion site, with the lesion site being the peak. The reinduced Wnts may be responsible for the well-known retraction of descending motor axons through the receptor Ryk (related receptor tyrosine kinases). Wnt signaling is an appealing new therapeutic target for $\mathrm{CNS}$ repair. The mechanisms regulating the re-induction are unknown but will be informative for therapeutic design.

Keywords: axon guidance, topographic mapping, spinal cord injury, axon regeneration, Wnt, Ryk, gradient

\section{GRADED EXPRESSION OF Wnts GUIDE AXONS ALONG THE ANTERIOR-POSTERIOR AXIS IN CNS DEVELOPMENT}

During development of the brain and the spinal cord, growing axons are directed by multiple guidance cues to their synaptic targets forming axon networks along the major anatomical axes, anterior-posterior (A-P), dorsal-ventral axes, and interiorsuperior. Axons along the A-P, or rostrocaudal, axis of the spinal cord establish the circuitry required for supraspinal control of motor function as well as for relaying sensory information to the brain. For long-distance projections, such as along the A-P axis, global gradients of molecular cues are necessary. Understanding the development of these long-distance connections between brain and spinal cord may provide insights for developing useful therapeutic interventions to repair these axons after injury.

The vertebrate commissural axons within the spinal cord are an excellent specimen to identify global A-P guidance cues. These axons have an initial dorsal-ventral trajectory to reach and cross the midline. Secreted attractants, Netrin-1, and Sonic Hedgehog (Shh) from the ventral midline, the floor plate, provide the dorsal-ventral cues (Kennedy et al., 1994; Serafini etal., 1994, 1996; Charron et al., 2003). Upon reaching the midline, commissural axons decussate and post-crossing commissural axons are repelled by Slits and Semaphorin 3B secreted from the floor plate (Zou et al., 2000). A global A-P guidance mechanism ensures the precise $90^{\circ}$ turn of commissural axons immediately after midline crossing. A decreasing anterior-to-posterior mRNA gradient of the diffusible morphogen Wnts (Wnt4, Wnt7b, Wnt5a, and Wnt7a) dictates the appropriate anterior turning of post-crossing commissural axons via the Frizzled3 receptor (Figure 1; Lyuksyutova et al., 2003). Disruption of the Wnt gradient or the loss of the Frizzled3 receptor leads to A-P guidance defects of post-crossing commissural axons (Lyuksyutova et al., 2003). Wnt proteins are also expressed in an A-P gradient (Onishi and Zou, unpublished results). The responsiveness of Frizzled 3 expressing commissural axons is dependent upon the activation of phosphatidylinositol3-kinase (PI3K) and atypical protein kinase $\mathrm{C}$, a key regulator of the apical-basal polarity signaling pathway (Wolf et al., 2008). In addition, planar cell polarity (PCP) signaling is required for anterior turning (Shafer et al., 2011). Therefore, Wnt attraction may be mediated by both apical-basal and PCP signaling cascades present in the growth cones of post-crossing commissural axons.

In contrast to the global gradients of Wnt proteins along the A-P axis in the spinal cord, Wnts $5 \mathrm{a}$ and $7 \mathrm{~b}$ are expressed in more complex gradients along the A-P axis in the developing hindbrain and midbrain (Fenstermaker et al., 2010; Blakely et al., 2011). These expression gradients control the orientation and growth of dopaminergic and serotonergic axons (Fenstermaker et al., 2010; Blakely et al., 2011), subpopulations of which contribute to supraspinal motor control (Holstege and Kuypers, 1987; Jordan et al., 2008). Orientation of midbrain monoaminergic axons also depends on the expression of components of the PCP signaling pathway (Fenstermaker et al., 2010).

Wnt 1 and Wnt5a mRNAs are expressed in decreasing anteriorto-posterior gradients within the early postnatal spinal cord during corticospinal tract development and repel corticospinal axons (Liu et al., 2005). The receptor protein tyrosine kinase member Derailed (Drl) mediates Wnt repulsion in Drosophila (Yoshikawa et al., 2003). Wnt5, expressed in the posterior commissure, repels anterior commissural axons that express Drl, while the posterior 


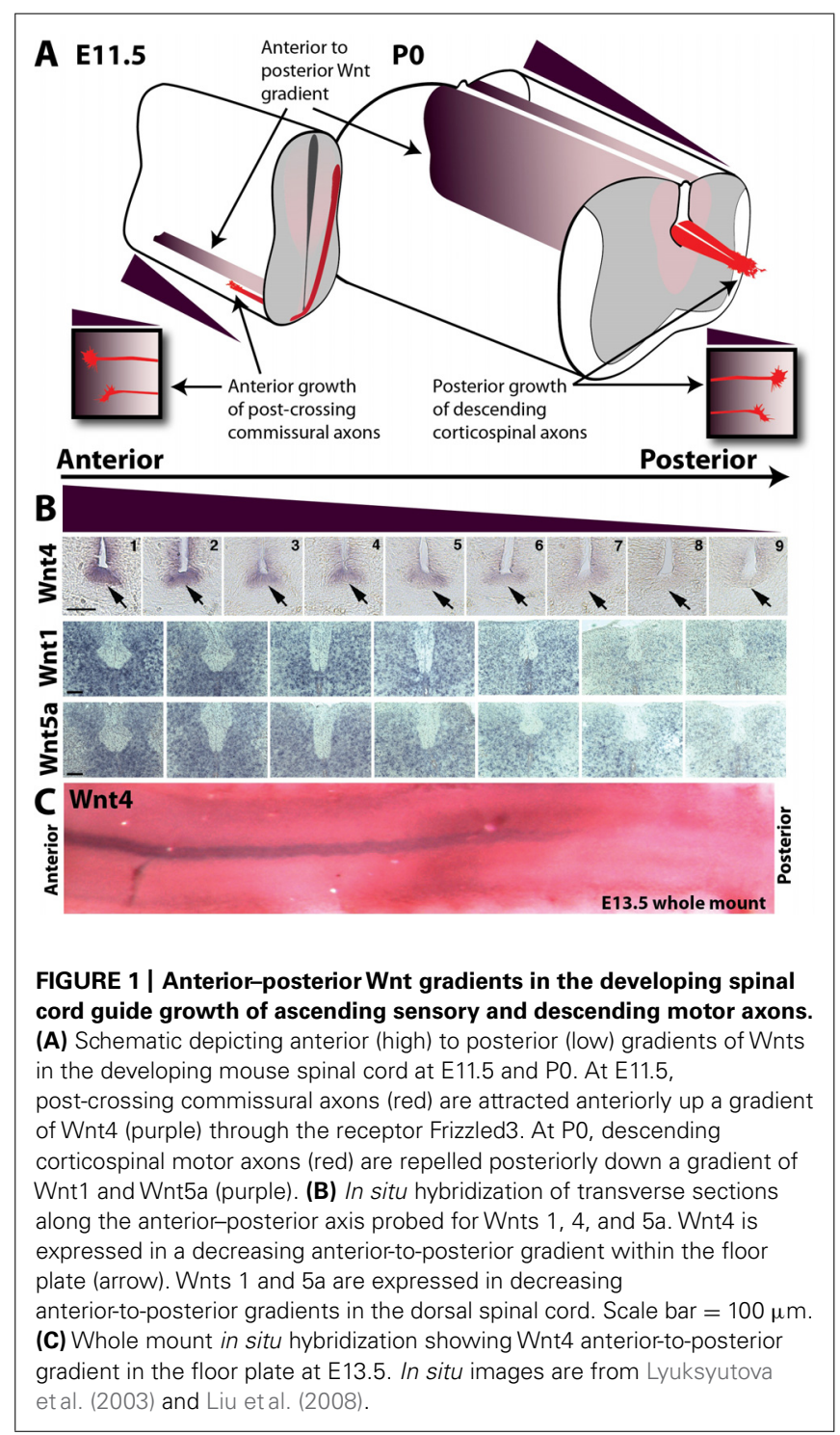

commissural axons do not express Drl and mis-expression of Drl results in repulsion from the posterior commissure and aberrant projection through the anterior commissure (Bonkowsky et al., 1999). Conversely, a loss of Drl results in mis-projection of anterior commissural axons through the posterior commissure (Bonkowsky etal., 1999). In the vertebrate nervous system, the Drl homolog, Ryk, is expressed in cortical neurons. Ryk in the descending corticospinal motor axons mediates Wnt repulsion and is required for the descending growth of CST axons down the spinal cord (Liu et al., 2005). Ryk has been shown required for outgrowth as well as repulsion of corticospinal axons along the A-P axis of the developing spinal cord (Liu et al., 2005; Li et al., 2009).

\section{Wnt GRADIENTS IN TOPOGRAPHIC MAPPING}

While work in the vertebrate spinal cord and invertebrate systems has demonstrated a role for Wnt morphogens in axon pathfinding, the vertebrate visual system utilizes Wnt expression gradients as positional cues to establish topographic connections. Wnt3 mRNA and protein are both expressed in a decreasing gradient along the medial (high) to lateral (low) axis within the developing chick tectum and mouse superior colliculus (Schmitt et al., 2006). This gradient of Wnt3 is used to establish a retinotopic map through the expression of the repulsive Wnt receptor Ryk in a ventral to dorsal decreasing gradient in retinal ganglia cells (Schmitt et al., 2006). The Wnt3 gradient was proposed to counterbalance the ephrin B1 mapping force. The specificity of retinal projections in D. melanogaster are also governed by the expression of Wnts, with DWnt4 expression guiding retinal axons to the ventral lamina to maintain a retinotopic map (Sato et al., 2006). Therefore, Wnt signaling may have a conserved role in topographic map formation. How Wnt expression gradients are established in these brain areas are currently unknown.

\section{RE-INDUCED Wnts FORM DIFFERENT GRADIENTS AFTER INJURY}

In the intact adult spinal cord, Wnt mRNA expression is undetectable, however after spinal cord injury, re-induction of Wnts 1,4 , and $5 \mathrm{a}$ occurs as evidenced by expression of mRNA in the cells immediately surrounding the lesion (Liu et al., 2008). The re-induced Wnts form gradients that peak at the lesion sites and decrease both anteriorly and posteriorly relative to the lesion sites. In addition to Wnts, other guidance molecules have also been found to be re-induced by spinal cord injury. Class 3 semaphorins and ephrins are both re-expressed in spinal cord lesion, although the role of the these guidance cues in the injury response has not been defined (Pasterkamp et al., 1999; Bundesen et al., 2003; Benson et al., 2005; Carmichael et al., 2005; Pasterkamp and Verhaagen, 2006). Wnt expression at the spinal cord injury site is coupled with re-expression of the repulsive receptor Ryk in corticospinal motor neurons where it is trafficked to the distal tip of the lesioned corticospinal axons (Liu et al., 2008). Inhibition of Wnt-Ryk signaling after spinal cord injury reduces the retraction of lesioned corticospinal axons from the injury site while concurrently promoting the sprouting of corticospinal axon collaterals within the spared spinal cord tissue (Liu et al., 2008). Another study showed similar results using a contusion model (Miyashita et al., 2009). Therefore, the re-induced Wnt gradients may be responsible for the long-range retraction of corticospinal tract axons following spinal cord injury.

In addition to the up-regulation of Ryk in injured corticospinal motor neurons, peripheral injury of the sciatic nerve results in the expression of Ryk in primary sensory neurons within the dorsal root ganglia (DRG; Li et al., 2008). Peripheral injury results in an increased intrinsic growth capacity of large-diameter sensory neurons in the DRG with a corresponding alteration of expression levels of thousands of genes (Richardson and Issa, 1984; Stam et al., 2007). This increased intrinsic growth capacity, due to the conditioning effect of the peripheral injury, allows for the regeneration of the central branch of primary sensory neurons along a permissive substrate (Richardson and Issa, 1984). Additionally, Ryk siRNA expression in developing DRG neurons reduces neurite outgrowth ex vivo and attenuates the Wnt3a-mediated outgrowth response of cultured DRG explants (Lu et al., 2004). In contusion injury experiments, grafting of fibroblasts transduced ex vivo to produce Wnt3a has been found to increase immunoreactivity 
of the regenerating axonal marker growth-associated protein 43 (GAP-43) near the lesion site (Suh et al., 2011).

In corticospinal motor neurons Wnt-Ryk signaling is able to promote both axon outgrowth as well as repulsive guidance through distinct signaling cascades (Li et al., 2009). This bifunctionality of Ryk may be active in DRG neurons as well, though it is currently unknown which neurons express Ryk after injury and what role the increased expression of the repulsive Wnt receptor Ryk may play in the peripheral conditioning lesion, if any.

\section{OTHER MORPHOGENS AFTER INJURY}

Wnts are not the only morphogens that are re-induced after spinal cord injury. Motor nuclei have been demonstrated to increase bone morphogenic protein (BMP) production following peripheral axotomy and potentially respond to BMP-2 protein infusion (Jin et al., 2003; Wang etal., 2007). Downstream of BMP-2 and 4 activation, BMP type I receptor mediates signaling through Smad1, 5, and 8 (Babitt et al., 2005). Smad1 activation in DRG neurons following peripheral injury is necessary for conditioning lesion mediated neurite outgrowth in vitro (Zou et al., 2009). Intraganglionic injection of BMP-2 or 4 had similar effects in vitro, mediating neurite outgrowth through phospho-Smad nuclear translocation, while AAV8-BMP4 delivery to DRG neurons has been shown to reduce sensory axon retraction from an injury site and promote limited regeneration (Zou et al., 2009; Parikh et al., 2011). BMP-2 signaling mediates trkC expression in developing sympathetic superior cervical ganglia neurons (Zhang et al., 1998), though it remains to be seen whether increased Smad activation following peripheral lesion underlies the increased capacity for central regeneration of large-diameter proprioceptive axons demonstrated in response to NT-3 gradients following peripheral conditioning lesion (Alto et al., 2009).

Conversely, BMP up-regulation following spinal cord injury has been proposed to inhibit regeneration of CNS axons (Setoguchi et al., 2004; Iichiro et al., 2008). In experiments delivering noggin

\section{REFERENCES}

Alto, L. T., Havton, L. A., Conner, J., Hollis, E. R. II, Ma, L., Blesch, A., and Tuszynski, M. H. (2009). Chemotropic guidance facilitates axonal regeneration and synapse formation after spinal cord injury. Nat. Neurosci. 12, 1106-1113.

Babitt, J. L., Zhang, Y., Samad, T. A., Xia, Y., Tang, J., Campagna, J. A., Schneyer, A. L., Woolf, C. J., and Lin, H. Y. (2005). Repulsive guidance molecule (RGMa), a DRAGON homologue, is a bone morphogenetic protein co-receptor. J. Biol. Chem. 280, 29820-29827.

Benson, M. D., Romero, M. I., Lush, M. E., Lu, Q. R., Henkemeyer, M., and Parada, L. F. (2005). Ephrin-B3 is a myelin-based inhibitor of neurite outgrowth. Proc. Natl. Acad. Sci. U.S.A. 102, 10694-10699.

Blakely, B. D., Bye, C. R., Fernando, C. V., Horne, M. K., Macheda, M. L.,
Stacker, S. A., Arenas, E., and Parish, C. L. (2011). Wnt5a regulates midbrain dopaminergic axon growth and guidance. PLoS ONE 6, e18373. doi: 10.1371/journal.pone.0018373

Bonkowsky, J. L., Yoshikawa, S., O’Keefe, D. D., Scully, A. L., and Thomas, J. B. (1999). Axon routing across the midline controlled by the Drosophila Derailed receptor. Nature 402, 540-544.

Bundesen, L. Q., Scheel, T. A., Bregman, B. S., and Kromer, L. F. (2003). Ephrin-B2 and EphB2 regulation of astrocyte-meningeal fibroblast interactions in response to spinal cord lesions in adult rats. J. Neurosci. 23, 7789-7800.

Bush, T. G., Puvanachandra, N., Horner, C. H., Polito, A., Ostenfeld, T., Svendsen, C. N., Mucke, L., Johnson, M. H., and Sofroniew, M. V. (1999). Leukocyte infiltration, neuronal degeneration, and neurite outgrowth after

producing neural precursor cells following compression injury to thoracic spinal cord, noggin was found to reduce astroglial cell fate of transplanted cells and proposed to mediate functional recovery, though the mechanism through which this recovery might occur is unclear (Setoguchi et al., 2004). Following contusion injury, a separate group found that infusion of noggin attenuated Smad phosphorylation in local neurons and either promoted corticospinal sprouting rostral to the lesion or reduced axonal dieback, though these effects are minimal and the mechanism remains unclear (Iichiro et al., 2008). There remains some contention in the interpretation of these results, however as a separate group reported that engraftment of noggin producing neural precursor cells following contusion or focal ischemic spinal cord injury not only were unable to alter the course of astroglial differentiation, but also resulted in increased neuronal loss and lesion volume compared to control precursor transplantation (Enzmann et al., 2005). This is similar to the detrimental effects of selectively ablating reactive astrogliosis after CNS injury, though there is limited neurite sprouting in astroglia free areas proximal to the site of injury (Bush et al., 1999; Faulkner et al., 2004).

\section{Wnts AS THERAPEUTIC TARGETS FOLLOWING SCI}

As Wnt signaling is globally required for axon guidance along the A-P axis and is part of the injury response, Wnt signaling is an attractive target for therapeutic intervention after injury to the long-distance projecting axons in the spinal cord. The re-establishment of Wnt gradients after spinal cord injury may be a useful strategy to promote the regeneration of injured supraspinal circuitry. The inhibition of Wnt-Ryk signaling has already demonstrated an enhancement of axonal growth and plasticity of corticospinal motor axons after injury (Liu et al., 2008). This induced axonal plasticity may provide a substrate for the formation of novel supraspinal motor circuits and improved functional recovery after injury. Understanding how Wnt expression is regulated will provide additional therapeutic tools.

ablation of scar-forming, reactive astrocytes in adult transgenic mice. Neuron 23, 297-308.

Carmichael, T. R., Carp, G. I., Welsh, N. D., and Kalk, W. J. (2005). Effective and accurate screening for diabetic retinopathy using a 60 degree mydriatic fundus camera. S. Afr. Med. J. 95, 57-61.

Charron, F., Stein, E., Jeong, J., McMahon, A. P., and Tessier-Lavigne, M. (2003). The morphogen sonic hedgehog is an axonal chemoattractant that collaborates with netrin-1 in midline axon guidance. Cell 113, 11-23.

Enzmann, G. U., Benton, R. L., Woock, J. P., Howard, R. M., Tsoulfas, P., and Whittemore, S. R. (2005). Consequences of noggin expression by neural stem, glial, and neuronal precursor cells engrafted into the injured spinal cord. Exp. Neurol. 195, 293-304.
Faulkner, J. R., Herrmann, J. E., Woo, M. J., Tansey, K. E., Doan, N. B., and Sofroniew, M. V. (2004). Reactive astrocytes protect tissue and preserve function after spinal cord injury. $J$. Neurosci. 24, 2143-2155.

Fenstermaker, A. G., Prasad, A. A., Bechara, A., Adolfs, Y., Tissir, F., Goffinet, A., Zou, Y., and Pasterkamp, R. J. (2010). Wnt/planar cell polarity signaling controls the anterior-posterior organization of monoaminergic axons in the brainstem. J. Neurosci. 30, 16053-16064.

Holstege, J. C., and Kuypers, H. G. J. M. (1987). Brainstem projections to spinal motoneurons: an update. Neuroscience 23, 809-821.

Iichiro, M., Junko, T., Katsuhiko, H., Naokatsu, S., and Toshihide, Y. (2008). BMP inhibition enhances axonal growth and functional recovery after spinal cord injury. J. Neurochem. 105, 1471-1479. 
Jin, Y., Suwa, F., Nie, X., Tipoe, G. L., Tamada, Y., Fang, Y. R., and Tanaka, T. (2003). Bone morphogenetic protein-2, 4, 6 and transforming growth factor-betal are induced in rat facial nuclei following motoneuron axotomy. Acta Histochem. Cytochem. 36, 231-237.

Jordan, L. M., Liu, J., Hedlund, P. B., Akay, T., and Pearson, K. G. (2008). Descending command systems for the initiation of locomotion in mammals. Brain Res. Rev. 57, 183-191.

Kennedy, T. E., Serafini, T., de la Torre, J. R., and Tessier-Lavigne, M. (1994). Netrins are diffusible chemotropic factors for commissural axons in the embryonic spinal cord. Cell 78, 425-435.

Li, L., Hutchins, B. I., and Kalil, K. (2009). Wnt5a induces simultaneous cortical axon outgrowth and repulsive axon guidance through distinct signaling mechanisms. J. Neurosci. 29, 5873-5883.

Li, X., Li, Y.-H., Yu, S., and Liu, Y. (2008). Upregulation of Ryk expression in rat dorsal root ganglia after peripheral nerve injury. Brain Res. Bull. 77, 178-184.

Liu, Y., Shi, J., Lu, C. C., Wang, Z. B., Lyuksyutova, A. I., Song, X. J., and Zou, Y. (2005). Rykmediated Wnt repulsion regulates posterior-directed growth of corticospinal tract. Nat. Neurosci. 8, 1151-1159.

Liu, Y., Wang, X., Lu, C. C., Kerman, R., Steward, O., Xu, X. M., and Zou, Y. (2008). Repulsive Wnt signaling inhibits axon regeneration after CNS injury. J. Neurosci. 28, 8376-8382.

Lu, W., Yamamoto, V., Ortega, B., and Baltimore, D. (2004). Mammalian Ryk is a Wnt coreceptor required for stimulation of neurite outgrowth. Cell 119, 97-108.

Lyuksyutova, A. I., Lu, C.-C., Milanesio, N., King, L. A., Guo, N., Wang, Y., Nathans, J., Tessier-Lavigne, M., and Zou, Y. (2003). Anterior-posterior guidance of commissural axons by Wnt-frizzled signaling. Science 302, 1984-1988.

Miyashita, T., Koda, M., Kitajo, K., Yamazaki, M., Takahashi, K., Kikuchi, A., and Yamashita, T. (2009). Wnt-Ryk signaling mediates axon growth inhibition and limits functional recovery after spinal cord injury. J. Neurotrauma 26, 955-964.

Parikh, P., Hao, Y., Hosseinkhani, M., Patil, S. B., Huntley, G. W., Tessier-Lavigne, M., and Zou, H. (2011). Regeneration of axons in injured spinal cord by activation of bone morphogenetic protein/Smadl signaling pathway in adult neurons. Proc. Natl. Acad. Sci. U.S.A. 108, E99-E107.

Pasterkamp, R. J., Giger, R. J., Ruitenberg, M. J., Holtmaat, A. J. G. D., De Wit, J., De Winter, F., and Verhaagen, J. (1999). Expression of the gene encoding the chemorepellent semaphorin III is induced in the fibroblast component of neural scar tissue formed following injuries of adult but not neonatal CNS. Mol. Cell. Neurosci. 13, 143-166.

Pasterkamp, R. J., and Verhaagen, J. (2006). Semaphorins in axon regeneration: developmental guidance molecules gone wrong? Philos. Trans. R. Soc. Lond. B Biol. Sci. 361, 1499-1511.

Richardson, P. M., and Issa, V. M. (1984). Peripheral injury enhances central regeneration of primary sensory neurones. Nature 309, 791-793.

Sato, M., Umetsu, D., Murakami, S., Yasugi, T., and Tabata, T. (2006). DWnt4 regulates the dorsoventral specificity of retinal projections in the Drosophila melanogaster visual system. Nat. Neurosci. 9, 67-75.

Schmitt, A. M., Shi, J., Wolf, A. M., Lu, C. C., King, L. A., and Zou, Y. (2006). Wnt-Ryk signalling mediates medial-lateral retinotectal topographic mapping. Nature 439, 31-37.

Serafini, T., Colamarino, S. A., Leonardo, E. D., Wang, H., Beddington,
R., Skarnes, W. C., and TessierLavigne, M. (1996). Netrin-1 is required for commissural axon guidance in the developing vertebrate nervous system. Cell 87, 1001-1014.

Serafini, T., Kennedy, T. E., Galko, M. J., Mirzayan, C., Jessell, T. M., and Tessier-Lavigne, M. (1994). The netrins define a family of axon outgrowth-promoting proteins homologous to $C$. elegans UNC-6. Cell 78, 409-424.

Setoguchi, T., Nakashima, K., Takizawa, T., Yanagisawa, M., Ochiai, W., Okabe, M., Yone, K., Komiya, S., and Taga, T. (2004). Treatment of spinal cord injury by transplantation of fetal neural precursor cells engineered to express BMP inhibitor. Exp. Neurol. 189, 33-44.

Shafer, B., Onishi, K., Lo, C. Colakoglu, G., and Zou, Y. (2011). Vangl2 promotes Wnt/planar cell polarity-like signaling by antagonizing Dvl1-mediated feedback inhibition in growth cone guidance. Dev. Cell 20, 177-191.

Stam, F. J., MacGillavry, H. D., Armstrong, N. J., de Gunst, M. C., Zhang, Y., van Kesteren, R. E., Smit, A. B., and Verhaagen, J. (2007). Identification of candidate transcriptional modulators involved in successful regeneration after nerve injury. Eur. J. Neurosci. 25, 3629-3637.

Suh, H., Min, J., Choi, K., Kim, S., Kim, K., and Jeon, S. (2011). Axonal regeneration effects of Wnt3a-secreting fibroblast transplantation in spinal cord-injured rats. Acta Neurochir. 153, 1003-1010.

Wang, Y.-L., Wang, D.-Z., Nie, X., Lei, D.-L., Liu, Y.-P., Zhang, Y.-J., Suwa, F., Tamada, Y., Fang, Y. R., and Jin, Y. (2007). The role of bone morphogenetic protein-2 in vivo in regeneration of peripheral nerves. Br. J. Oral Maxillofac. Surg. 45, 197-202.

Wolf, A. M., Lyuksyutova, A. I., Fenstermaker, A. G., Shafer, B., Lo, C. G., and Zou, Y. (2008). Phosphatidylinositol3-kinase-atypical protein kinase
C signaling is required for Wnt attraction and anterior-posterior axon guidance. J. Neurosci. 28 , 3456-3467.

Yoshikawa, S., McKinnon, R. D., Kokel, M., and Thomas, J. B. (2003). Wnt-mediated axon guidance via the Drosophila Derailed receptor. Nature 422, 583-588.

Zhang, D., Mehler, M. F., Song, Q., and Kessler, J. A. (1998). Development of bone morphogenetic protein receptors in the nervous system and possible roles in regulating trkC expression. J. Neurosci. 18, 3314-3326.

Zou, H., Ho, C., Wong, K., and TessierLavigne, M. (2009). Axotomyinduced Smadl activation promotes axonal growth in adult sensory neurons. J. Neurosci. 29, 7116-7123.

Zou, Y., Stoeckli, E., Chen, H., and Tessier-Lavigne, M. (2000). Squeezing axons out of the gray matter: a role for slit and semaphorin proteins from midline and ventral spinal cord. Cell 102, 363-375.

Conflict of Interest Statement: The authors declare that the research was conducted in the absence of any commercial or financial relationships that could be construed as a potential conflict of interest.

Received: 02 December 2011; paper pending published: 21 December 2011; accepted: 11 January 2012; published online: 02 February 2012.

Citation: Hollis ER II and Zou Y (2012) Expression of the Wnt signaling system in central nervous system axon guidance and regeneration. Front. Mol. Neurosci. 5:5. doi: 10.3389/fnmol.2012.00005

Copyright (c) 2012 Hollis II and Zou. This is an open-access article distributed under the terms of the Creative Commons Attribution Non Commercial License, which permits non-commercial use, distribution, and reproduction in other forums, provided the original authors and source are credited. 